\title{
Machining Parameter Optimization of EVA Foam Orthotic Shoe Insoles
}

\author{
Paulus Wisnu Anggoro ${ }^{1, *}$, Abet Adhy Anthony ${ }^{1}$, Mohammad Tauviqirrahman ${ }^{2}$ Jamari $^{2}$, \\ Athanasius Priharyoto Bayuseno ${ }^{2}$, Aylie $\mathrm{Han}^{3}$ \\ ${ }^{1}$ Department of Industrial Engineering, University of Atma Jaya Yogyakarta, D.I. Yogyakarta, Indonesia \\ ${ }^{2}$ Department of Mechanical Engineering, University of Diponegoro, Semarang, Central Java, Indonesia \\ ${ }^{3}$ Department of Civil Engineering, University of Diponegoro, Semarang, Central Java, Indonesia \\ Received 16 December 2019; received in revised form 03 March 2020; accepted 19 May 2020 \\ DOI: https://doi.org/10.46604/ijeti.2020.5099
}

\begin{abstract}
In this study, ethylene-vinyl acetate (EVA) foam orthotic shoe insoles with different surface roughnesses (Ra) are investigated in terms of CNC milling strategy. Based on a hybrid Taguchi-response surface methodology (TM-RSM) approach, machining parameters, including tool path strategy, spindle speed, feed rate, and step over, as well as material hardness, are of particular interest. The main aim of this work is to develop mathematical models and determine the optimum machining parameters. Experiments are conducted on a CNC milling machine with a standard milling cutter and run under dry coolants. The optimal conditions are established based on TM and then used to determine the optimum values in the RSM modeling. The main finding of the present work is that there are significant improvements in the Ra, by up $0.24 \%$ and $4.13 \%$, and machining time, by up $0.43 \%$ and $0.41 \%$, obtained with TM-RSM in comparison to TM analysis.
\end{abstract}

Keywords: shoe insole, EVA foam, CNC milling, surface roughness (Ra), machining time

\section{Introduction}

There are three types of shoe soles: the bottom of the shoe that contacts directly with the ground (outsole), the bottom of the shoes attached to the outsole, and the insole is the inside of the shoe that contacts directly with the patient's feet. Among them, the second provides comfort to the foot during exertion (middle sole), and the insole of the third is located on the inside of the shoe between the outsole and upper shoe. The shoe insole is in direct contact with the human foot while doing daily activities such as walking, running, and jumping. This part is very important in determining whether the user or patient feels comfortable when wearing shoes.

Types of rubber include isobutylene-isoprene rubber, chloroprene rubber, nitrile rubber, silicone rubber, polyurethane, natural rubber, ethylene-propylene rubber, and polybutadiene [1]. While the rubber materials were used as orthotic shoe insoles in the manufacturing industry for EVA, some researchers [2-7] reported that EVA foam shaped like a rubber material, known as EVA foam rubber, is also a popular raw material for insole shoe orthotics (ISO) in the shoe industry. This material proved widely used in the engineering design process for shoe insole manufacturing because of useful properties including good elastomer properties, lightweight, formability, and quite easily processed manufacturing on CNC milling machines. EVA foam rubber is a copolymer formed from the monomers ethylene and vinyl acetate (VA) with resin and rubber [8]. EVA rubber foam also has many applications in sports and medical engineering because it is very good as an energy absorber and has a high fracture toughness relative to other polymers [9]. Besides, this material is consistently used in advanced composites for

* Corresponding author. E-mail address: pauluswisnuanggoro@ymail.com Tel.: +62-857-294-99-575 
specialized application insole shoe orthotics for a patient with diabetes (ISO diabetes). As a result, these materials are gaining widespread acceptance in the footwear sector at this time because the industry can provide a lighter weight shoe with high comfort, robustness, and durability [9].

ISO diabetes used in footwear to reduce pain and mechanical load on the patient's leg would be better if manufactured using CNC machines. This machine produces ISO diabetes with high surface quality, accuracy, and precision. To generate an ISO product with these requirements, parameters need to be optimized on the optimal cutting CNC machine and its supporting equipment. The imprecise results of conventional foam box methods, which were carried out by several orthotics laboratories in Indonesia, can be minimized using reverse engineering, CAD, CAM, and CNC [6-7]. Surface quality and Ta initially ranging from $\mathrm{Ra}=20-30 \mu \mathrm{m}$ and 1-week working time can be reduced to $\mathrm{Ra}=5-9 \mu \mathrm{m}$ and five to seven hours/pair of orthotic shoes (ISO diabetes). To achieve this highly desirable result, the use of optimization techniques to determine precise machining parameter settings and obtain an optimal response is the research done in this paper. Two statistical methods were used to resolve this problem, Taguchi methodology (TM) and response surface methodology (RSM). These methods were used to help researchers and an ISO engineer solve the problems of determining the insole designs when EVA foam rubber is used.

The objective of this paper is to develop a mathematical model and optimize the manufacturing process parameters using the hybrid TM-RSM approach. This hybrid approach was chosen to develop a mathematical model and optimize the orthotic shoe insole cutting parameters in a CNC milling process on the EVA rubber foam material.

\section{Methods}

\subsection{The 3D design of the shoe insole orthotics}

Three types of orthotic shoe insole designs that fit the contour of diabetes mellitus patient's legs were manufactured on a CNC milling machine. According to the results of the work carried out previously [10], reverse innovative design (RID) methods were used to develop a 3D model shoe orthotic insole with the aid of 3D scanning (Handyscan 700TM) in which the surface modeling base curve of the three insole designs can be explored using the CAD software PowerSHAPE 2017. The results of insole design for precise geometric tolerances enlarged along the XY axis ranged from 0.75 to $1.50 \mathrm{~mm}$. Three types of orthotics shoe insole designs that fit with the foot of patients who have were successfully obtained by previous researchers [5-6] and are shown in Fig. 1.

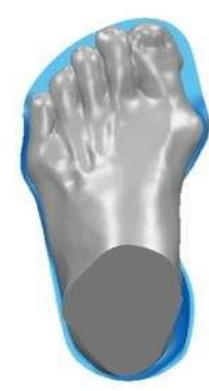

0.0

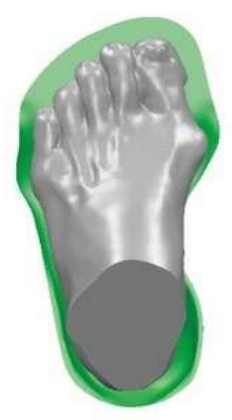

0.75

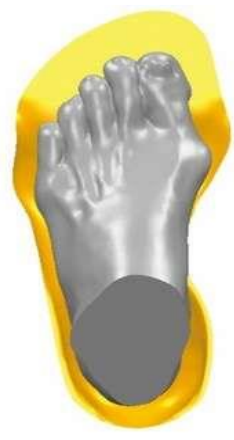

1.50

Fig. 1 Top view of 3D CAD model shoe insoles with several size tolerances

\subsection{Condition cutting parameters and design of experiments}

Six machining parameters were selected and evaluated, namely toolpath strategy (A), spindle speed (B), feed rate (C), step over (D), EVA foam with variable hardness (E), and the type of insole design with wide tolerance (F). Based on all machining parameters in Table 1, the optimal experiment design in this research used the Taguchi methods with Minitab v2017 was an orthogonal array $\mathrm{OA} \mathrm{L}_{27} 3^{6}$ and is shown in Table 2. 


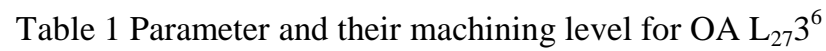

\begin{tabular}{|c|c|c|c|}
\hline \multirow{2}{*}{ Factor } & \multicolumn{3}{|c|}{ Level } \\
\cline { 2 - 4 } & 1 & 2 & 3 \\
\hline $\mathrm{A}$ & ${\text { Raster } 90^{\circ}}^{\circ}$ & Raster $45^{\circ}$ & Step and Shallow \\
\hline $\mathrm{B}$ & $14000 \mathrm{rpm}$ & $14500 \mathrm{rpm}$ & $15000 \mathrm{rpm}$ \\
\hline $\mathrm{C}$ & $800 \mathrm{~mm} / \mathrm{min}$ & $850 \mathrm{~mm} / \mathrm{min}$ & $900 \mathrm{~mm} / \mathrm{min}$ \\
\hline $\mathrm{D}$ & $0.20 \mathrm{~mm}$ & $0.25 \mathrm{~mm}$ & $0.30 \mathrm{~mm}$ \\
\hline $\mathrm{E}$ & $20-35 \mathrm{HRc}(\$ 31 / \mathrm{sheet})$ & $40-50 \mathrm{HRc}(\$ 37 / \mathrm{sheet})$ & $50-60 \mathrm{HRc}(\$ 47 / \mathrm{sheet})$ \\
\hline $\mathrm{F}$ & $0.50 \mathrm{~mm}$ & $0.75 \mathrm{~mm}$ & $1.00 \mathrm{~mm}$ \\
\hline
\end{tabular}

Table 2 Response data surface roughness $(\mathrm{Ra})$ and Ta for $\mathrm{OA} \mathrm{L}_{27} 3^{6}$

\begin{tabular}{|c|c|c|c|c|c|c|c|c|c|c|}
\hline \multirow{3}{*}{$\mathrm{N} \exp$} & \multicolumn{6}{|c|}{ Uncoded value of factor } & \multirow{3}{*}{ Insole patient 1} & \multirow{3}{*}{$\begin{array}{c}\mathrm{Ra} \\
\text { Insole patient } 2 \\
\mu \mathrm{m}\end{array}$} & \multirow{3}{*}{$\begin{array}{c}\text { Ta } \\
\text { Patient 1 } \\
\text { Minutes }\end{array}$} & \multirow{3}{*}{$\begin{array}{c}\text { Ta } \\
\text { Patient } 2 \\
\text { Minutes }\end{array}$} \\
\hline & \multirow{2}{*}{ A } & \multirow{2}{*}{$\mathrm{B}$} & \multirow{2}{*}{$\mathrm{C}$} & \multirow{2}{*}{$\mathrm{D}$} & \multirow{2}{*}{$\mathrm{E}$} & \multirow{2}{*}{$\mathrm{F}$} & & & & \\
\hline & & & & & & & & & & \\
\hline 1 & 1 & 1 & 1 & 1 & 1 & 1 & 7.671 & 8.594 & 323.32 & 336.39 \\
\hline 2 & 1 & 1 & 1 & 1 & 2 & 2 & 8.995 & 9.436 & 319.40 & 334.45 \\
\hline 3 & 1 & 1 & 1 & 1 & 3 & 3 & 9.252 & 8.081 & 321.80 & 333.83 \\
\hline 4 & 1 & 2 & 2 & 2 & 1 & 1 & 6.969 & 7.716 & 256.44 & 269.35 \\
\hline 5 & 1 & 2 & 2 & 2 & 2 & 2 & 8.011 & 8.800 & 254.24 & 268.34 \\
\hline 6 & 1 & 2 & 2 & 2 & 3 & 3 & 8.368 & 6.618 & 254.20 & 268.52 \\
\hline 7 & 1 & 3 & 3 & 3 & 1 & 1 & 7.812 & 8.027 & 214.96 & 229.95 \\
\hline 8 & 1 & 3 & 3 & 3 & 2 & 2 & 8.324 & 9.286 & 212.77 & 229.77 \\
\hline 9 & 1 & 3 & 3 & 3 & 3 & 3 & 8.527 & 8.319 & 213.89 & 229.80 \\
\hline 10 & 2 & 1 & 2 & 3 & 1 & 2 & 7.162 & 7.881 & 229.52 & 245.17 \\
\hline 11 & 2 & 1 & 2 & 3 & 2 & 3 & 8.198 & 9.225 & 228.58 & 244.57 \\
\hline 12 & 2 & 1 & 2 & 3 & 3 & 1 & 8.080 & 7.496 & 227.78 & 243.88 \\
\hline 13 & 2 & 2 & 3 & 1 & 1 & 2 & 7.967 & 8.395 & 301.10 & 315.20 \\
\hline 14 & 2 & 2 & 3 & 1 & 2 & 3 & 9.330 & 8.771 & 298.35 & 313.75 \\
\hline 15 & 2 & 2 & 3 & 1 & 3 & 1 & 7.659 & 8.897 & 297.52 & 312.44 \\
\hline 16 & 2 & 3 & 1 & 2 & 1 & 2 & 8.432 & 7.557 & 276.97 & 290.96 \\
\hline 17 & 2 & 3 & 1 & 2 & 2 & 3 & 7.934 & 7.361 & 274.80 & 289.85 \\
\hline 18 & 2 & 3 & 1 & 2 & 3 & 1 & 8.417 & 6.890 & 272.55 & 288.78 \\
\hline 19 & 3 & 1 & 3 & 2 & 1 & 3 & 7.963 & 8.151 & 273.59 & 289.62 \\
\hline 20 & 3 & 1 & 3 & 2 & 2 & 1 & 8.588 & 9.061 & 321.67 & 337.44 \\
\hline 21 & 3 & 1 & 3 & 2 & 3 & 2 & 8.822 & 7.970 & 270.45 & 283.65 \\
\hline 22 & 3 & 2 & 1 & 3 & 1 & 3 & 8.165 & 7.983 & 271.33 & 286.35 \\
\hline 23 & 3 & 2 & 1 & 3 & 2 & 1 & 7.974 & 7.881 & 326.90 & 343.99 \\
\hline 24 & 3 & 2 & 1 & 3 & 3 & 2 & 7.554 & 8.047 & 267.33 & 282.33 \\
\hline 25 & 3 & 3 & 2 & 1 & 1 & 3 & 8.009 & 6.850 & 327.28 & 341.77 \\
\hline 26 & 3 & 3 & 2 & 1 & 2 & 1 & 7.599 & 8.489 & 382.09 & 398.11 \\
\hline 27 & 3 & 3 & 2 & 1 & 3 & 2 & 8.372 & 9.008 & 322.65 & 338.53 \\
\hline
\end{tabular}

Table 3 Response surface roughness $(\mathrm{Ra})$ for $\mathrm{S} / \mathrm{N}$ ratios $(\mathrm{dB})$ and the Means effects $(\mathrm{m})$

\begin{tabular}{|c|c|c|c|c|c|c|c|c|c|c|}
\hline \multirow{3}{*}{ Control factor } & \multicolumn{5}{|c|}{$\begin{array}{l}\text { Surface roughness Ra } \\
\quad(\text { Insole patient } 1)\end{array}$} & \multicolumn{5}{|c|}{$\begin{array}{c}\text { Surface roughness Ra } \\
\text { (Insole patient 2) }\end{array}$} \\
\hline & level 1 & level 2 & level 3 & SN Ra & Delta & level 1 & level 2 & level 3 & SN Ra & Delta \\
\hline & \multicolumn{3}{|c|}{ Mean $(\mu \mathrm{m})$} & $(\mathrm{dB})$ & $(\mu \mathrm{m})$ & \multicolumn{3}{|c|}{ Mean $(\mu \mathrm{m})$} & $(\mathrm{dB})$ & $(\mu \mathrm{m})$ \\
\hline A & 8.214 & 8.095 & 8.131 & 26618.0 & 0.119 & 8.320 & 8.053 & 8.181 & 5637.1 & 0.267 \\
\hline $\mathrm{B}$ & 8.304 & 8.158 & 8.011 & 4664.21 & 0.293 & 8.433 & 7.976 & 8.123 & 1848.7 & 0.456 \\
\hline $\mathrm{C}$ & 7.863 & 8.277 & 8.332 & 1517.19 & 0.469 & 8.009 & 7.981 & 8.542 & 1004.9 & 0.561 \\
\hline $\mathrm{D}$ & 8.317 & 7.989 & 8.167 & 3692.73 & 0.328 & 8.502 & 7.791 & 8.238 & 776.7 & 0.711 \\
\hline$E$ & 7.794 & 8.328 & 8.350 & 1007.68 & 0.556 & 7.906 & 8.701 & 7.925 & 487.28 & 0.795 \\
\hline $\mathrm{F}$ & 8.193 & 7.863 & 8.443 & 1182.39 & 0.580 & 8.117 & 7.932 & 8.486 & 1260. & 0.554 \\
\hline
\end{tabular}


The average Ra for orthotic shoe insoles was measured with a Ra tester (Mark Surf PS 1) in Table 2, and the Ra value obtained is Ra value on average for the second leg of the patient. The response of processing time (Ta) and surface roughness (Ra) for $\mathrm{S} / \mathrm{N}$ ratios and means effects are shown in Tables (3)-(4).

Table 4 Response processing time (Ta) for $\mathrm{S} / \mathrm{N}$ ratios (dB) and the effects of Means (hours)

\begin{tabular}{|c|c|c|c|c|c|c|c|c|c|c|}
\hline \multirow{3}{*}{ Control factor } & \multicolumn{4}{|c|}{ Insole processing time $\left(\mathrm{T}_{\mathrm{A} 1}\right)$} & \multicolumn{5}{c|}{ Insole processing time $\left(\mathrm{T}_{\mathrm{A} 2}\right)$} \\
\cline { 2 - 11 } & \multicolumn{4}{|c|}{ (Patient 1) } & \multicolumn{5}{c|}{ (Patient 2) } \\
\cline { 2 - 11 } & level 1 & level 2 & level 3 & $\mathrm{SN} \mathrm{Ra}$ & Delta & level 1 & level 2 & level 3 & $\mathrm{SN}$ Ra & Delta \\
\cline { 2 - 11 } & \multicolumn{3}{|c|}{ Mean (hour) } & (dB) & (hour) & \multicolumn{3}{|c|}{ Mean (hour) } & $(\mathrm{dB})$ & $($ hour) \\
\hline $\mathrm{A}$ & $\mathbf{4 . 3 9 1}$ & 4.458 & 5.118 & -12.73 & 0.727 & $\mathbf{4 . 6 3 0}$ & 4.707 & 5.374 & -13.21 & 0.743 \\
\hline $\mathrm{B}$ & 4.659 & 4.680 & $\mathbf{4 . 6 2 7}$ & -13.13 & 0.054 & 4.906 & 4.926 & $\mathbf{4 . 8 7 9}$ & -13.61 & 0.048 \\
\hline $\mathrm{C}$ & 4.916 & 4,598 & $\mathbf{4 . 4 5 2}$ & -12.87 & 0.463 & 5.156 & 4.848 & $\mathbf{4 . 7 0 7}$ & -13.36 & 0.449 \\
\hline $\mathrm{D}$ & 5.359 & 4.546 & $\mathbf{4 . 0 6 1}$ & -12.09 & 1.298 & 5.601 & 4.784 & $\mathbf{4 . 3 2 6}$ & -12.65 & 1.275 \\
\hline $\mathrm{E}$ & 4.583 & 4.849 & $\mathbf{4 . 5 3 4}$ & -13.05 & 0.316 & 4.824 & 5.106 & $\mathbf{4 . 7 8 1}$ & -13.52 & 0.325 \\
\hline $\mathrm{F}$ & 4.858 & $\mathbf{4 . 5 4 5}$ & 4.563 & -13.08 & 0.313 & 5.112 & $\mathbf{4 . 7 9 3}$ & 4.806 & -13.55 & 0.318 \\
\hline
\end{tabular}

\subsection{Material specimens, machine tools, and cutting tools specification}

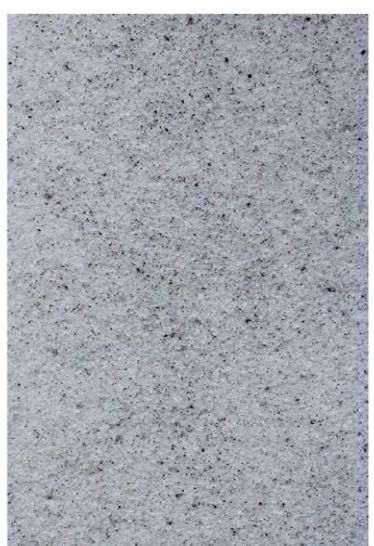

Leve1 1 (20-30 HRc)

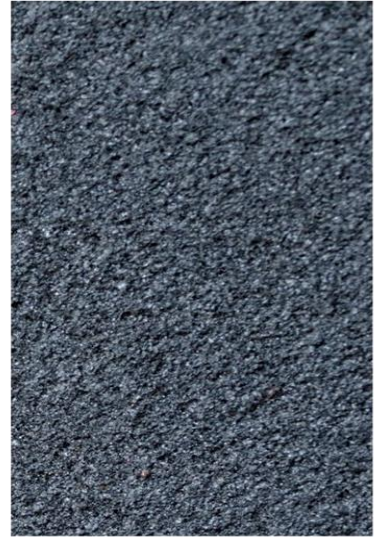

Level 2 (35 45 HRc)

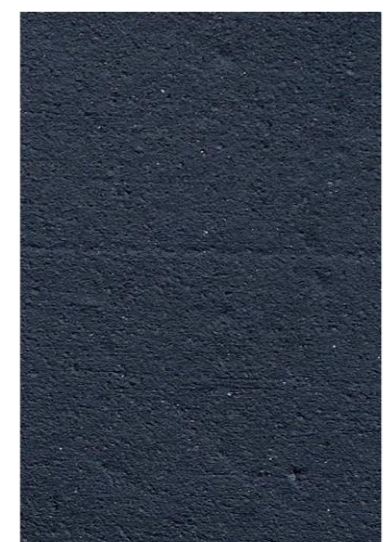

Level 3 (50-60 HRc)

(a) Three types of EVA rubber foam with different hardness

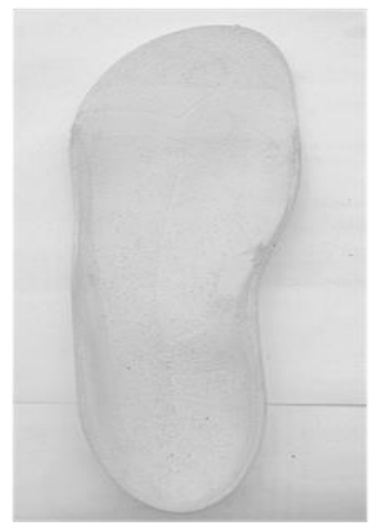

Level 1 (20-30 HRc)

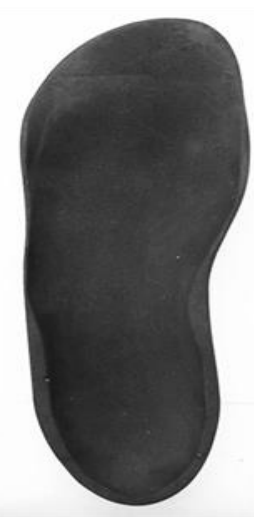

Level 2 (35 $45 \mathrm{HRc}$ )

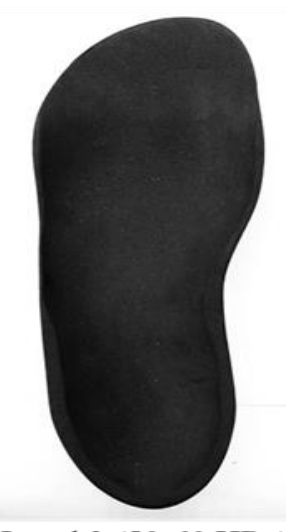

Level 3 (50-60 HRc)

(b) Insole product with various harnesses

Fig. 2 Research outputs

The EVA foam rubber size used in the experiments for insole manufacture in the CNC milling process was $250 \mathrm{~mm}$ x 95 $\mathrm{mm} \times 23 \mathrm{~mm}$. This material has a hardness in the range of 20-60 HRc, was measured by using a shore hardness tester (Asker CL-150). Three types of EVA foam rubber identified based on three hardness levels (Level 1 20-35 HRc, Level 2 35-45 HRc, and Level 3 50-60 HRc). The material prices for 1200 × 2400 x $30 \mathrm{~mm}$ sheets in the local market in Jakarta, Indonesia are presented in Table 1. Besides, EVA foam rubber also has a density of $55-65 \mathrm{~kg} / \mathrm{m}^{3}$, the nominal size on the market of around $2000 \times 1000 \mathrm{~mm}$, thickness (separate) of 3-36 mm, the tensile strength of $800 \mathrm{kPa}$, and tear strength of $4.5 \mathrm{kN} / \mathrm{m}$ [2]. The test 
CNC milling process on the EVA foam rubber made the used maximum spindle speeds up to 17,000 rpm and $100 \mathrm{~W}$ DC-power spindle motors. The used cutting tools were made from carbide milling cutter endmill type SECO [93060F] and ball-nose milling cutter [JS533060D1B0Z3 -NXT]. Material specimens, outputs, and a flowchart of the research are presented in Figs. (2)-(3).

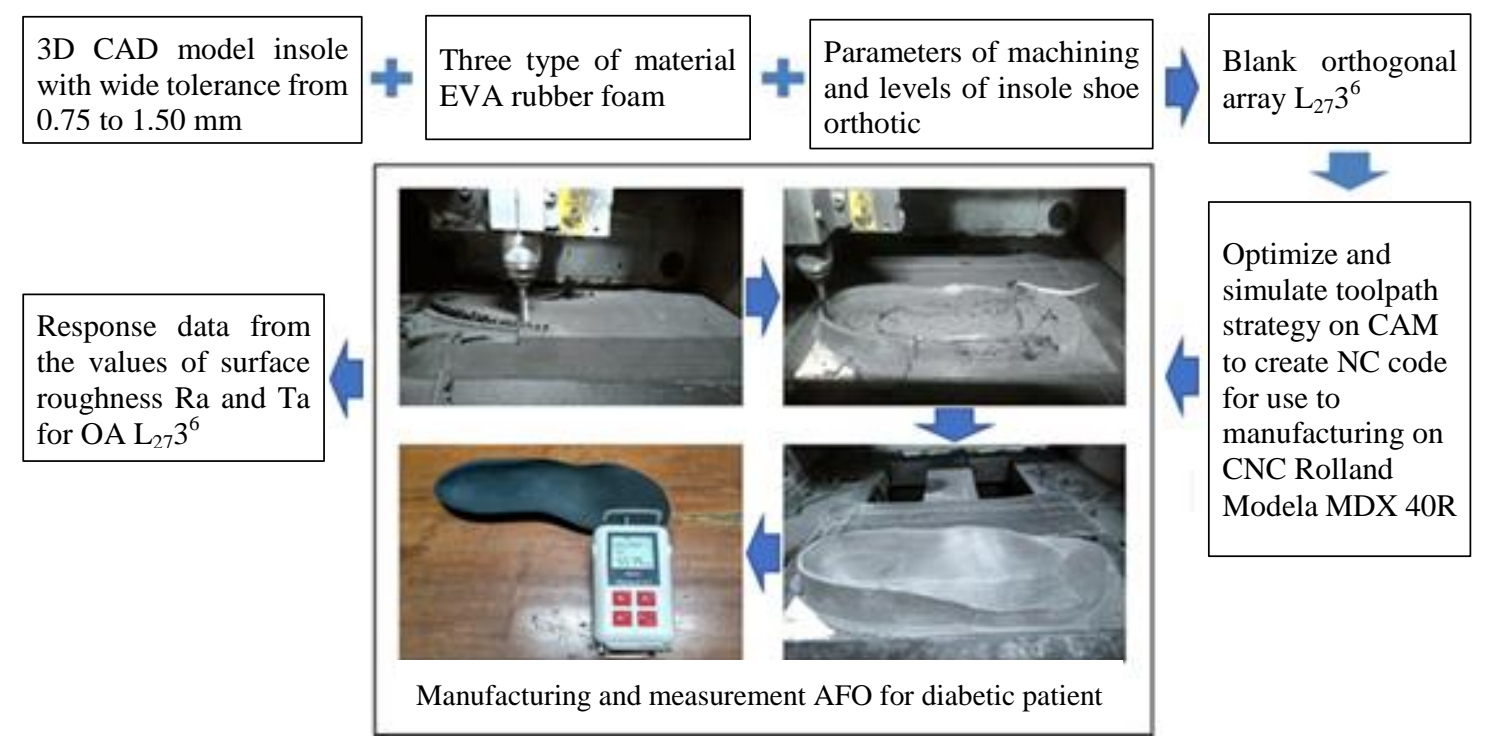

(a) Experimental
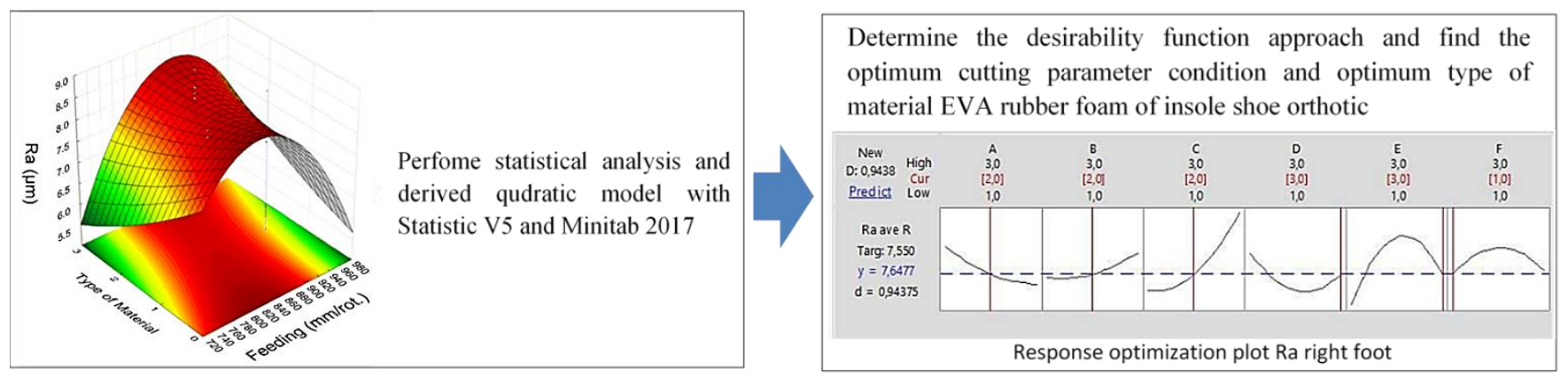

(b) Optimization modeling with the hybrid approach to TM-RSM

Fig. 3 Manufacturing optimization flow diagram, ISO diabetes

\section{Results and Discussion}

In this study, the value of Ra was obtained from experiments varying the cutting parameters for the orthotic shoe insole manufacturing process in a Roland MDX 40R CNC machine, and the results are shown in Table 2. The effect or influence arising from any level of the factors on quality characteristics was analyzed using the signal-to-noise ratio. Different values of SNR between the maximum and minimum (main effect) are presented in Tables (3)-(4). For Ra of the shoe insole orthotics for Patient 2, the optimum value can be achieved if conditions are set at Level 2 for factors toolpath strategy (A), spindle speed (B), feed rate (C), depth of cut (D) and insole design type (F), while the EVA foam rubber hardness factor (E) is set at Level 1. Therefore, two cutting parameter optimal conditions for minimal Ra (orthotics shoe insole for Patients 1 and Patient 2 suffering from diabetes) can be simplified according to a combination of factors, $A_{2} B_{3} C_{1} D_{2} E_{1} F_{2}$ and $A_{2} B_{2} C_{2} D_{2} E_{1} F_{2}(T a b l e ~ 3)$. The optimal setting parameter $\mathrm{A}_{1} \mathrm{~B}_{3} \mathrm{C}_{3} \mathrm{D}_{3} \mathrm{E}_{3} \mathrm{~F}_{2}$ (Table 4) meant Level 1 for toolpath strategy (A); Level 3 for spindle speed (B), feed rate (C), depth of cut (D), as well as the type of EVA rubber foam (E); and Level 2 for the insole design (F). The results of this combination are presented in Tables (3)-(4), where the means and the SNR values with the quality characteristic of the Taguchi method are smaller, it can be proved better in this paper. The values of contributions (\%) for the response Ra (insole for Patient 1 and Patient 2) respectively is $78.62 \%$ and $89.00 \%$ (with error $21.376 \%$ and $11.00 \%$ ), while for the working time it is $99.98 \%$ and $100 \%$ on ANOVA (analysis of variance) in Tables (5)-(6). Furthermore, the percentage contribution to the linear model, 
the square model, and the interaction between factors on Patient 1 of the Ra in Table 5 is $37.05 \%$ (linear), 15.24\% (squares), and $15.13 \%$ (interaction between factors). Factor E and F contribute more significantly (17.20\% and 17.04\%), followed by Factor C (1.73\%), B (1.21\%), D (0.95\%), and A (0.42\%). Similarly, the ANOVA values for Ra for Patient 2 give the result that Factor $\mathrm{C}$ is the most effective factor, contributing 6.54\%, followed by Factor F (2,29\%), D (1.27\%), E (0.59\%), B (0.30\%), and A $(0.22 \%)$ are shown in Table 6. Correspondingly, Ra of the lowest orthotic shoe insole can be achieved by an optimum condition milling process (factors feed rate and the type of material EVA foam rubber), and also by the results of research work has been published [4, 11-12].

Table 5 ANOVA for surface roughness Ra for Patient 1

\begin{tabular}{|c|c|c|c|c|c|c|}
\hline Variation of Source & DoF & \multirow{2}{*}{ SS } & MS & \multirow{2}{*}{ F-value } & P-value & Contribution \\
\hline & & & & & & $(\%)$ \\
\hline Model & 13 & 6.353 & 0.4887 & 3.68 & 0.013 & 78.62 \\
\hline Linear & 6 & 2.994 & 0.4990 & 3.76 & 0.022 & 37.05 \\
\hline A & 1 & 0.034 & 0.0339 & 0.26 & 0.406 & 0.42 \\
\hline B & 1 & 0.098 & 0.0979 & 0.74 & 0.538 & 1.21 \\
\hline C & 1 & 0.140 & 0.1402 & 1.05 & 0.323 & 1.73 \\
\hline D & 1 & 0.077 & 0.0771 & 0.58 & 0.460 & 0.95 \\
\hline E & 1 & 1.390 & 1.3901 & 10.5 & 0.007 & 17.20 \\
\hline F & 1 & 1.377 & 1.3768 & 10.4 & 0.007 & 17.04 \\
\hline Square & 2 & 1.232 & 0.6159 & 4.63 & 0.03 & 15.24 \\
\hline C*C & 1 & 0.839 & 0.839 & 6.31 & 0.026 & 10.38 \\
\hline E*E & 1 & 0.393 & 0.3930 & 2.96 & 0.109 & 4.86 \\
\hline 2-Way Interaction & 7 & 1.223 & 0.2791 & 2.1 & 0.130 & 15.13 \\
\hline A*B & 1 & 0.127 & 0.127 & 0.96 & 0.346 & 1.57 \\
\hline A*C & 1 & 0.290 & 0.0033 & 2.19 & 0.163 & 3.59 \\
\hline B*F & 1 & 0.264 & 0.2638 & 1.99 & 0.182 & 3.26 \\
\hline C*E & 1 & 0.509 & 0.5086 & 3.83 & 0.072 & 6.29 \\
\hline D*F & 1 & 1.068 & 1.068 & 8.04 & 0.014 & 13.21 \\
\hline Error & 13 & 1.727 & 0.1329 & & & 21.376 \\
\hline Total & 26 & 8.081 & & & & 100 \\
\hline & & & & & \\
\hline
\end{tabular}

Table 6 ANOVA for surface roughness Ra for Patient 2

\begin{tabular}{|c|c|c|c|c|c|c|}
\hline Variation of Source & DoF & SS & MS & \multirow{2}{*}{ F-value } & P-value & Contribution \\
\cline { 6 - 7 } & & & & & & $(\%)$ \\
\hline Model & 16 & 8.8423 & 0.5526 & 5.06 & 0.049 & 89.00 \\
\hline Linear & 6 & 1.1329 & 0.1882 & 1.73 & 0.212 & 11.40 \\
\hline A & 1 & 0.0214 & 0.0214 & 0.2 & 0.668 & 0.22 \\
\hline B & 1 & 0.0299 & 0.0299 & 0.27 & 0.612 & 0.30 \\
\hline C & 1 & 0.6500 & 0.6501 & 5.95 & 0.035 & 6.54 \\
\hline D & 1 & 0.1258 & 0.1258 & 1.15 & 0.309 & 1.27 \\
\hline E & 1 & 0.0588 & 0.0588 & 0.54 & 0.480 & 0.59 \\
\hline F & 1 & 0.2274 & 0.2274 & 2.08 & 0.180 & 2.29 \\
\hline Square & 3 & 4.7855 & 1.5952 & 14.6 & 0.001 & 48.17 \\
\hline A*A & 1 & 1.4859 & 1.4859 & 13.6 & 0.004 & 14.96 \\
\hline D*D & 1 & 0.1969 & 0.1969 & 1.8 & 0.209 & 1.98 \\
\hline E*E & 1 & 2.5920 & 2.5920 & 23.73 & 0.001 & 26.09 \\
\hline 2-Way Interaction & 7 & 3.09987 & 0.44284 & 4.05 & 0.023 & 31.20 \\
\hline A*F & 1 & 1.15284 & 1.15284 & 10.55 & 0.009 & 11.60 \\
\hline B*E & 1 & 0.2085 & 0.2085 & 1.91 & 0.197 & 2.10 \\
\hline B*F & 1 & 0.2170 & 0.2170 & 1.99 & 0.189 & 2.18 \\
\hline C*D & 1 & 0.3737 & 0.3737 & 3.42 & 0.094 & 3.76 \\
\hline D*F & 1 & 0.2452 & 0.2452 & 2.24 & 0.165 & 2.47 \\
\hline E*F & 1 & 0.29503 & 0.29503 & 2.7 & 0.131 & 2.97 \\
\hline Error & 10 & 1.092 & 0.1093 & & & 11.00 \\
\hline Total & 26 & 9.935 & & & & 100.00 \\
\hline & & & & & &
\end{tabular}


RSM was conducted in this paper for modeling and analyzing several variables that have a significant relationship between the dependent variable and one or more of the independent variables defined in the study. In this way, the experimental results of the EVA foam rubber milling process in CNC machines can be developed into a mathematical model with response $\mathrm{Ra}$ and $\mathrm{Ta}$. The second-order regression model can be seen in Eqs. (1)-(4). This regression model is a function of six machining parameter variables (A, B, C, D, E, and F), which were set in Table 1, and can be expressed using RSM with Minitab software v17.

$$
\begin{aligned}
R a_{(\text {patient } 2)}= & 77.983+0.39 A-0.0186 B+0.133 C+134.941 D-8.016 E-0.217 F \\
& +0.0000119 A B+0.000679 A C-2.623 A D+0.0758 A E-0.325 A F+0.0000056 B C \\
& -0.0039 B D+0.000217 B+0.000368 B F-0.104 C D+0.00532 C E-0.00508 C F \\
& +0.1501 D E+13.582 D F-0.199 E F-0.1005 A^{2}+0.00000049 B^{2}-0.00012 C^{2} \\
& +13.39 D^{2}+0.069 E^{2}-1.436 F^{2} \\
& -104.433-0.155 A+0.0058 B+0.1403 C+168.123 D+0.726 E+1.104 F \\
& +0.000071 A B-0.00093 A C+1.682 A D+0.2 A E+0.0754 A F-0.00000116 B C \\
& -0.00445 B D-0.0000678 B E-0.00025 B F-0.0785 C D-0.000984 C E \\
& -0.0123 C F-1.245 D E-8.659 D F+0.27 E F-0.2548 A^{2}-0.2548 A^{2} \\
& -0.000000072 B^{2}-0.000063 C^{2}-69.614 D^{2}+0.0504 E^{2}-3.76 F^{2} \\
& =5604.97-3.03 A^{2}-0.000002 B^{2}+0.00203 C^{2}+4157.03 D^{2}+0.017 E^{2}+103.08 F^{2} \\
& -97.395 A-0.25 B-8.18 C+85.5 D+1.36 E-27.33 F+0.015 A B-0.0163 A C \\
& +75.275 A D+0.083 A E+22.35 A F+0.00038 B C-0.13 B D+0.00019 B E-0.011 B F \\
& -0.651 C D-0.006 C E-0.006 C F-3.146 D E+226.42 D F+0.085 E F \\
& +32.8 A D+0.0775 A E+21.92 A F+0.00026 B C-0.227 B D+0.00018 B E-0.0132 B F \\
& +175.74 A-0.0507 B-6.125 C+2678.92 D+0.235 E+119.739 F+0.00107 A B-0.22 A C \\
T_{(\text {patient } 2)} & 2749.34-6.427 A^{2}-0.0000037 B^{2}+0.00176 C^{2}+319.05 D^{2}+0.0015 E^{2}+133.45 F^{2} \\
& +178 C D-0.002 C E-0.35 C F-7.51 D E+549.02 D F+0.471 F E \\
& \\
&
\end{aligned}
$$

In this study, the response to $\mathrm{Ra}$ in both patients provides $\mathrm{R} 2$ of $97.80 \%$ (Patient 1) and 98.20\% (Patient 2). In this case, the value of R2 was close to $100 \%$, as desired for this experiment. Therefore, the two regression models that were formed above can be used to predict the $\mathrm{Ra}$ at certain design parameters.

For a better understanding of the interaction effect of all the machining variables on Ra, 3D-plot curves for the measured response can be developed using Eqs. (1)-(4). The 3D surface graphs illustrate the relationship between cutting parameters and the response $\mathrm{Ra}$ is shown in Figs. (4)-(5).

The predictability of the mathematical model developed by researchers was performed separately for each experiment, which provides the optimum Ra value for each insole right leg and left leg at $8.538 \mu \mathrm{m}$ and $7.828 \mu \mathrm{m}$, respectively. The optimal Ra value has been obtained precisely and significantly to the optimal cutting conditions that have been set: toolpath strategy (raster machining $\left.45^{\circ}\right)$, spindle speed $(14,500 \mathrm{rpm})$, feed rate $(850 \mathrm{~mm} / \mathrm{min})$, step over $(0.25 \mathrm{~mm})$, EVA foam with hardness 20-35 HRc (Level 1), and the type of insole design with wide tolerance set on $0.75 \mathrm{~mm}$. At these conditions, the value of Ra is predicted to follow a trend that is similar to the experimental value in the manufacturing process in the CNC milling machine with an average absolute percentage error for the second insole less than 3.6\% (Tables 7-8) [11-13]. 


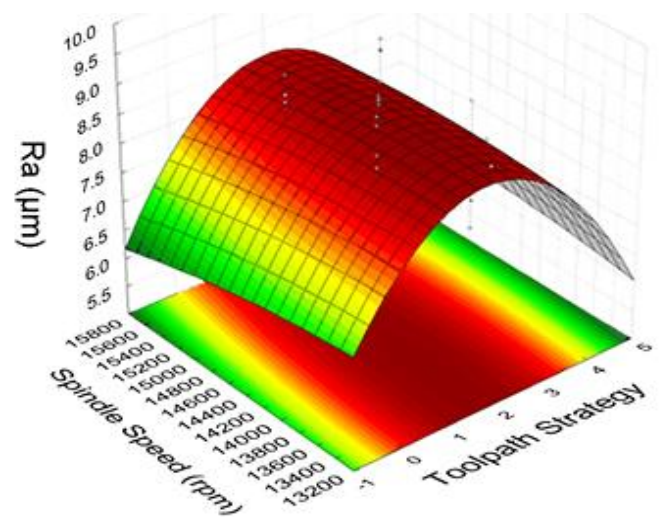

(a) Spindle feed-toolpath strategy for left foot of patient no. 1

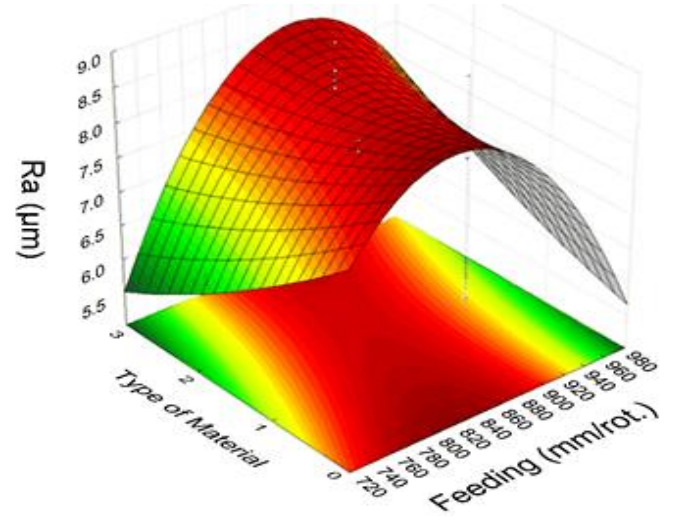

(c) Type material-feeding for left foot of patient no. 2

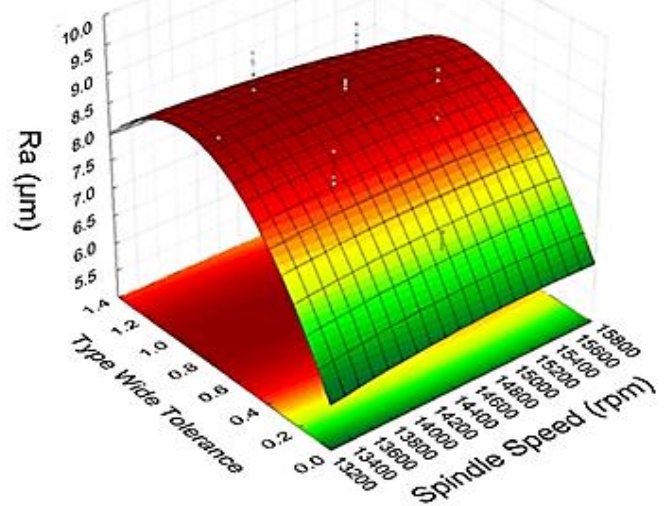

(b) Spindle feed-toolpath strategy for right foot of patient no. 1

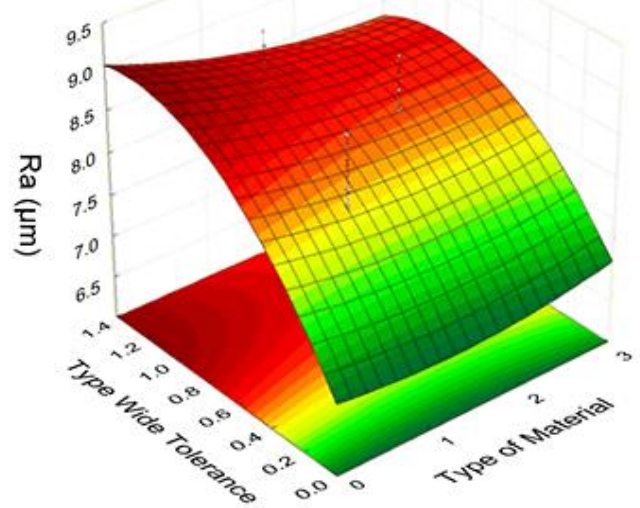

(d) Type wide tolerance-type of material for right foot of patient no. 2

Fig. 4 The 3D plot curve of surface roughness (Ra)

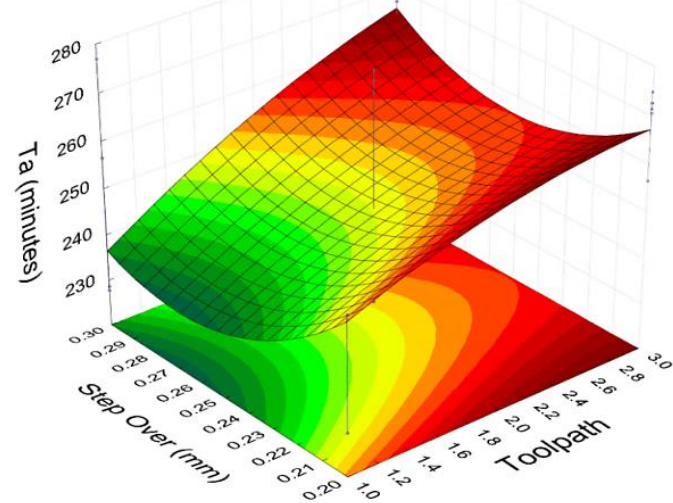

(a) Type EVA foam-Toolpath for left foot of patient no. 1

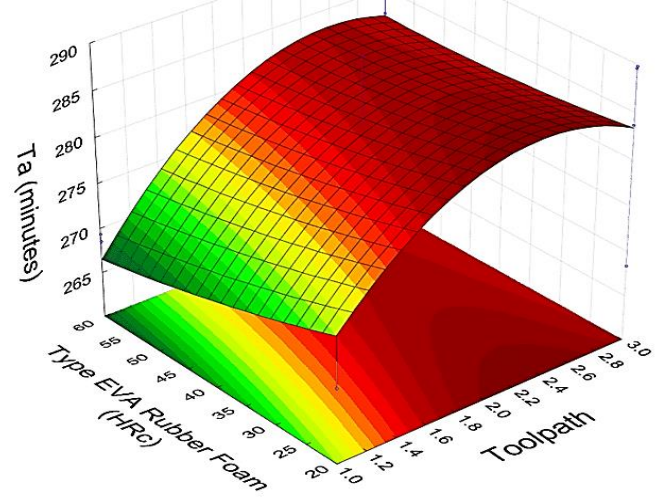

(c) Type EVA foam-Toolpath for left foot of patient no. 2

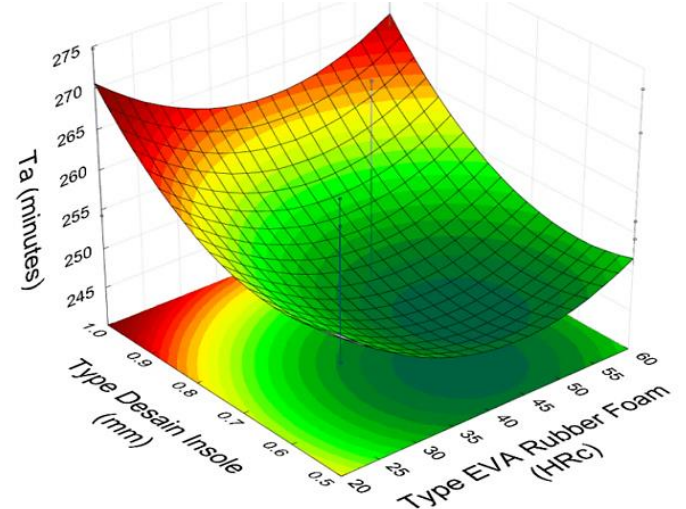

(b) Type design insole-Type EVA foam for right foot of patient no. 1

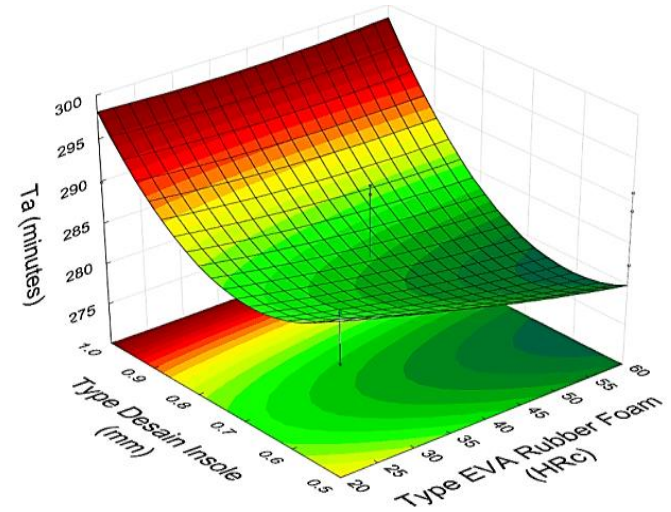

(d) Design insole-type Type EVA foam for right foot of patient no. 2

Fig. 5 The 3D plot curve of Time machining (Ta) 
In this approach, the measured parameter of each predicted response can be transformed into a dimensionless desirability value $(\mathrm{dF})[14]$. The scale of the desirability function is between 0 and 1 . If the value of $\mathrm{DF}=0$ or close to 0 , the response is considered to be unacceptable. If the value of $\mathrm{DF}=1$ or close to 1 , the response is considered to be optimal.

A confirmation experiment was performed at the optimum conditions predicted and yielded Ra values of $8.432 \mu \mathrm{m}$ and $7.557 \mu \mathrm{m}$ (insole for Patient 1 and Patient 2, respectively) as well as Tm values of $213.89 \mathrm{~min}$. and 229.80 min. (Table 7). The ability to successfully predict from the model also tested in optimal conditions. The predictive values of $\mathrm{Ra}=8.538 \mu \mathrm{m}$ and $7.828 \mu \mathrm{m}$ were obtained from the model (Table 8). Optimal results obtained with different optimization techniques (TM and TM-RSM) were compared and there was a significant improvement in the surface which was finished with the hybrid approach. Predictive and comparative analyses of optimal conditions in this study are all summarized in Table 7 . Based on the observations in Table 8, the hybrid approach of optimization techniques with TM-RSM provided $0.24 \%$ and $1.56 \%$ improvement of the surface finishing process for the same shoe orthotics insole compared with the optimal results obtained from the TM approach. The TM-RSM hybrid approach provides significant values for the absolute error of shoe orthotic insoles for the left leg and right foot for both patients with diabetes mellitus, $11.31 \%$, and 4.85\%, respectively the desirability function for the Ra shoe orthotic insoles of the left leg and right for both the patients are presented in Fig. 6.

Table 7 Optimum parameters and test results confirm the experimental results with predicted Ra and Ta values using the response surface method $(\mathrm{RSM})$

\begin{tabular}{|c|c|c|c|c|c|c|c|c|c|}
\hline \multirow{3}{*}{$\begin{array}{c}\text { Optimal Cutting } \\
\text { Parameters } \\
\text { Conditions }\end{array}$} & \multirow{3}{*}{ Toolpath } & $\begin{array}{l}\text { Spindle } \\
\text { Speed }\end{array}$ & Feed Rate & $\begin{array}{l}\text { Step } \\
\text { Over }\end{array}$ & $\begin{array}{c}\text { Type of } \\
\text { Material } \\
\text { EVA }\end{array}$ & $\begin{array}{c}\text { Width } \\
\text { Tolerance }\end{array}$ & \multicolumn{2}{|c|}{ Ra_Based } & \multirow{3}{*}{$\begin{array}{c}\text { Percentage } \\
\text { Error }(\%)\end{array}$} \\
\hline & & \multirow{2}{*}{ (RPM) } & \multirow{2}{*}{$(\mathrm{mm} / \mathrm{min})$} & \multirow{2}{*}{$(\mathrm{mm})$} & \multirow{2}{*}{ (HRc) } & \multirow{2}{*}{$(\mathrm{mm})$} & Exp. & RSM & \\
\hline & & & & & & & \multicolumn{2}{|c|}{$(\mu \mathrm{m})$} & \\
\hline $\mathbf{A}_{2} \mathbf{B}_{2} \mathbf{C}_{2} \mathbf{D}_{2} \mathbf{E}_{1} \mathbf{F}_{2}$ & raster $45^{\circ}$ & 14,500 & 850 & 0.25 & $20-35$ & 0.75 & 8.432 & 8.538 & 1.26 \\
\hline $\mathbf{A}_{2} \mathbf{B}_{2} \mathbf{C}_{2} \mathbf{D}_{2} \mathbf{E}_{1} \mathbf{F}_{2}$ & raster $45^{\circ}$ & 14,500 & 850 & 0.25 & $20-35$ & 0.75 & 7.557 & 7.828 & 3.59 \\
\hline \multirow{3}{*}{$\begin{array}{l}\text { Optimal Cutting } \\
\text { Parameters } \\
\text { Conditions }\end{array}$} & \multirow{3}{*}{ Toolpath } & $\begin{array}{c}\text { spindle } \\
\text { Speed }\end{array}$ & feed Rate & $\begin{array}{l}\text { Step } \\
\text { over }\end{array}$ & $\begin{array}{c}\text { Type of } \\
\text { Material } \\
\text { EVA }\end{array}$ & $\begin{array}{c}\text { width } \\
\text { Tolerance }\end{array}$ & Ta_H & ased & Percentage \\
\hline & & \multirow{2}{*}{ (RPM) } & \multirow{2}{*}{$(\mathrm{mm} / \mathrm{min})$} & \multirow{2}{*}{$(\mathrm{mm})$} & \multirow{2}{*}{ (HRc) } & \multirow{2}{*}{$(\mathrm{mm})$} & Exp. & RSM & \\
\hline & & & & & & & \multicolumn{2}{|c|}{$(\mu \mathrm{m})$} & \\
\hline$A_{1} B_{3} C_{3} D_{3} E_{3} F_{2}$ & raster & 15,000 & 900 & 0.3 & $50-60$ & 0.75 & 213.89 & 216.56 & 1.25 \\
\hline$A_{1} B_{3} C_{3} D_{3} E_{3} F_{2}$ & raster & 15,000 & 900 & 0.3 & $50-60$ & 0.75 & 229.80 & 237.36 & 3.29 \\
\hline
\end{tabular}

Table 8 Comparison of Ra optimum and experimental results

\begin{tabular}{|c|c|c|c|c|c|c|}
\hline \multirow{4}{*}{ Optimization techniques } & \multicolumn{4}{|c|}{$\mathrm{Ra}$} & \multirow{2}{*}{\multicolumn{2}{|c|}{ Absolute \% error }} \\
\hline & \multicolumn{2}{|c|}{ Optimal } & \multicolumn{2}{|c|}{ predicted } & & \\
\hline & Patient 1 & Patient 2 & Patient 1 & Patient 2 & Dotiont 1 & Dotiont ? \\
\hline & $(\mu \mathrm{m})$ & $(\mu \mathrm{m})$ & $(\mu \mathrm{m})$ & $(\mu \mathrm{m})$ & Patient 1 & Patient 2 \\
\hline Taguchi Approach (TM) & 7.554 & 7.332 & 6.936 & 6.752 & 8.18 & 7.68 \\
\hline Approach TM-RSM & 7.572 & 7.448 & 8.538 & 7.828 & 11.31 & 4.85 \\
\hline Percentage $(\%)$ improvement & 0.24 & 1.56 & - & - & & \\
\hline \multirow{4}{*}{ Optimization techniques } & \multicolumn{4}{|c|}{$\mathrm{Ta}$} & & \\
\hline & \multicolumn{2}{|c|}{ Optimal } & \multicolumn{2}{|c|}{ predicted } & \multicolumn{2}{|c|}{ Absolute \% error } \\
\hline & Patient 1 & Patient 2 & Patient 1 & Patient 2 & \multirow{2}{*}{ Patient 1} & \multirow{2}{*}{ Patient 2} \\
\hline & (minutes) & (minutes) & (minutes) & (minutes) & & \\
\hline Taguchi Approach (TM) & 213.89 & 229.8 & 179.04 & 212.46 & 16.29 & 7.55 \\
\hline Approach TM-RSM & 276.63 & 286.17 & 217 & 237.36 & 21.71 & 17.06 \\
\hline Percentage $(\%)$ improvement & 22.68 & 19.70 & - & - & & \\
\hline
\end{tabular}


In the study, the desirability functions Ta was selected as "the smaller the better" because the optimal minimum Ta can be achieved in the machining parameters in the optimum CNC milling machine. The desirability functions of "the smaller the better" can be shown in Fig. 6, the patient's optimal value, Ta1, in the model was reached at 309.22 minutes, which gives a chance to the toolpath 2.09 (Levels 2-3), $14075.39 \mathrm{rpm}$ spindle speed (Level 1), $936.88 \mathrm{~mm} / \mathrm{min}$ feed rate (Level 3), $0.28 \mathrm{~mm}$ step over (Level 3), a material with hardness $76.67 \mathrm{HRc}$ (Level 3), and the 0.82 design (Level 3). The optimal value for model Ta2 patients was achieved at 286.098 minutes and was set at 2.15 (Levels 2-3), $14935.86 \mathrm{rpm}$ spindle speed (Level 3 ), 859.88 $\mathrm{mm} / \mathrm{min}$ feed rate (Level 3), $0.23 \mathrm{~mm}$ step over (Level 2), a material with hardness $11.01 \mathrm{HRc}$ (level 1), and 0.75 design type (Level 2). The Ta desirability values for both patients reached values of 1.00. As a result, the response is considered perfect for the target value. The results of this paper had been proven by researchers [6-7, 15-16] in the process of design, manufacturing, and fabricating orthotic shoes comprising shoe last, the shoe insole and, special orthotics for diabetes patients.

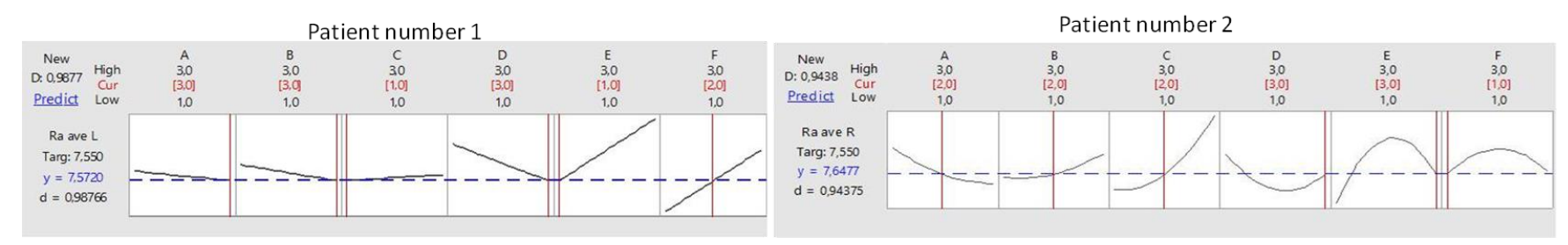

(a) Surface roughness $(\mathrm{Ra})$

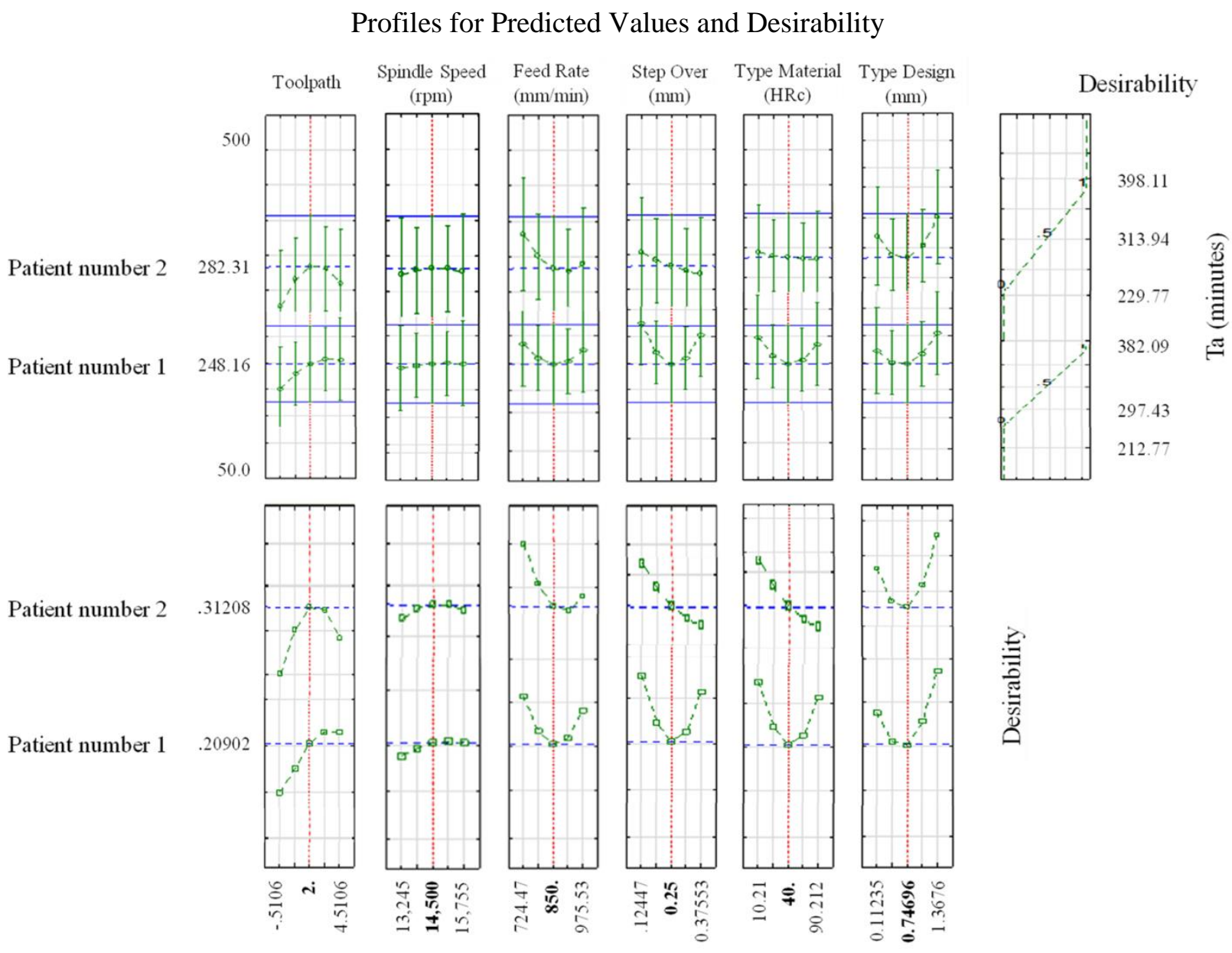

(b) Machining time (Ta)

Fig. 6 Profile predicted values and desirability with TM-RSM hybrid methods

( $\mathrm{D}=$ composite desirability; $\mathrm{d}=$ individual desirability; High = highest value parameter; Cur = optimal current value of control parameter; Low = lowest value parameter, $\mathrm{y}=$ response parameter, $\mathrm{Ra}=$ average surface roughness; $\mathrm{A}=$ toolpath strategy; $\mathrm{B}=$ spindle speed; $\mathrm{C}=$ feed rate; $\mathrm{D}=$ step over; $\mathrm{E}=\mathrm{EVA}$ foams with variable hardness; $\mathrm{F}=$ typical design of insoles with wide tolerance) 


\section{Conclusion}

In this research, a TM_RSM approach was successfully implemented to create a mathematical model and optimize the milling process for ISO diabetes made of EVA foam rubber in a $\mathrm{CNC}$ milling machine. Based on the discussion mentioned earlier, the conclusions can be drawn as follows:

(1) Ra at optimum cutting conditions based on the TM approach shows an optimum insole Ra value of $6.936 \mu \mathrm{m}$ for Patient 1 and $6.752 \mu \mathrm{m}$ for Patient 2. The optimal combination is in Position $\mathrm{A}_{2} \mathrm{~B}_{3} \mathrm{C}_{1} \mathrm{D}_{2} \mathrm{E}_{1} \mathrm{~F}_{2}$ and $\mathrm{A}_{2} \mathrm{~B}_{2} \mathrm{C}_{2} \mathrm{D}_{2} \mathrm{E}_{1} \mathrm{~F}_{2}$.

(2) The optimum cutting conditions RSM-based approach shows the value of the surface roughness was $\mathrm{Ra}=7.828 \mu \mathrm{m}$ (Patient 1) and $\mathrm{Ra}=8.538 \mu \mathrm{m}$ (Patient 2), both were under the cutting parameters in $\mathrm{A}_{2} \mathrm{~B}_{2} \mathrm{C}_{2} \mathrm{D}_{2} \mathrm{E}_{1} \mathrm{~F}_{2}$.

(3) The TM-RSM-based hybrid approach produces optimal machining parameter conditions at position: toolpath strategy (raster $45^{\circ}$ and step \& shallow machining), spindle speed (14,500-15,000 rpm), feed rate (800-900 mm / min), step over is $0.3 \mathrm{~mm}$, the hardness of EVA foam material (20-35 HRc and 50-60 HRc), and ISO diabetes tolerance range (0.50 to 0.75 $\mathrm{mm}$ ). The Ra optimum value of each was predicted at $\mathrm{Ra}=7.572 \mu \mathrm{m}$ and $7.648 \mu \mathrm{m}$ for the insole left leg and right leg, respectively.

(4) The surface quality for the TM-RSM hybrid method is better than the other methods ( $0.24 \%$ for left foot insole and $4.13 \%$ for right foot insole) when compared to the optimum value of the Taguchi method.

(5) Both methods (TM approach and TM-RSM approach) are very beneficial for data optimization of the results of CNC milling machine operation, which aims to reduce the time and cost of manufacture, to produce orthotic shoe insoles for a patient with diabetes.

\section{Acknowledgment}

We would like to gratefully thank you for PUTP Polytechnic ATMI Surakarta, Tribology Laboratory of the Department of Mechanical Engineering, University of Diponegoro in Semarang and CV EMA Pacific Surakarta that already provide full support in the form of infrastructure support CAM, CAD, and RE during the design, developed process as well as the writing of this paper.

This research was funded by Directorate of Research and Community Service, Directorate General of Research and Development Strengthening, Ministry of Research, Technology and Higher Education Fiscal Year 2019, grant Number: 257-93/UN7.P4.3/PP/2019 and Number: 257-73/UN7.P4.3/PP/2019. Letter of agreement for the implementation of research acceleration grants at the Atma Jaya University Yogyakarta, Number: 382/HB-PEN PGB/LPPM/XI/2019.

\section{Conflicts of Interest}

The authors declare no conflict of interest.

\section{References}

[1] Y. P. Wu, Y. Ma, Y. Q. Wang, and L. Q. Zhang, "Effects of characteristics of rubber, mixing and vulcanization on the structure and properties of rubber/clay nanocomposites by melt blending," Macromolecular Materials and Engineering, vol. 289, no. 10, pp. 890-894, October 2004.

[2] E. T. Nurit, W. Ety, H. F. Yifat, and G. Amit, "Role of EVA viscoelastic properties in the protective performance of a sport shoe: computational studies," Journal Bio-Medical \& Material Engineering, vol. 16, no. 5, pp. 289-299, 2006.

[3] Y. R. Jeng, S. Liu, and H-T. Yau, "Designing experimental methods to predict the expansion ratio of EVA foam material and using finite element simulation to estimate the shoe expansion shape," Material Transactions, vol. 53, no. 9, pp. 1685-1688, September 2012. 
[4] P. W. Anggoro, B. Bawono, A. Widiyanto, Jamari, and A. P. Bayuseno, "Parameter optimization of strategies at the CNC milling machines rolland model MDX 40R cam surface roughness against shoe orthotic insole made of EVA foam rubber," International Journal of Mechatronics and Mechanical Engineering, vol. 6, no. 4, pp. 96-104, 2016.

[5] P. W. Anggoro, E. Saputra, M. Tauviqirrahman, Jamari, and A. P. Bayuseno, "A 3-dimensional finite element analysis of the shoe insole orthotics for foot deformities," International Journal of Applied Engineering Research, vol. 12, no. 15, pp. 5254-5260, 2017.

[6] P. W. Anggoro, M. Tauviqirrahman, Jamari, A. P. Bayuseno, B. Bawono, and M. M. Avellina, "Computer-aided reverse engineering system in the design and production of orthotic insole shoes for patients with diabetes," Cogent Engineering, vol. 5, no. 1, pp. 1-20, June 2018.

[7] P. W.Anggoro, M. Tauviqirrahman, Jamari, A. P. Bayuseno, J. Wibowo, and Y. D. Saputro, "The optimal design and manufacturing of shoe last product for an ankle foot orthotic for the patient with diabetes," International Journal of Manufacturing, Materials, and Mechanical Engineering, vol. 9, no. 2, pp. 62-80, April 2019.

[8] M. Pracella, Minhaz-Ul Haque, and V. Md. Alvarez, "Functionalization, compatibilization, and properties of polyolefin composites with natural fibers,” Polymers Journal, vol. 2, no. 4, pp. 554-574, November 2010.

[9] Y. Shimazaki, S. Nozu, and T. Inoue, "Shock-absorption properties of functionally graded EVA laminates for footwear design,” Polymer Testing, vol. 54, pp. 98-103, July 2016.

[10] X. Ye, H. Liu, L. Chen, Z. Chen, X. Pan, and S. Zhang, "Reverse innovative design - an integrated product design methodology," Computer Aided Design, vol. 40, no. 7, pp. 812-827, August 2008.

[11] M. Sarikaya and A. Gullu, "Taguchi design and response surface methodology-based analyses of machining parameters in CNC turning under MQL," Journal of Clean Production, vol. 65, pp. 604-616, 2014.

[12] I. Asiltürk and S. Neseli, "Multi-response optimization of CNC turning parameters via Taguchi method-based response surface analysis,” Measurement, vol. 45, no. 4, pp. 785-794, January 2012.

[13] R. N. Yadav, "A hybrid approach of taguchi-response surface methodology for modeling and optimization of duplex turning process,” Measurement, vol. 100, pp. 131-138, January 2017.

[14] A. N. Sait, S. Aravindan, and A. N. Haq, "Optimization of machining parameters of glassefibre-reinforce plastics analysis technique using Taguchi,” International Journal of Advanced Manufacturing Techniques, vol. 43, pp. 581-589, 2009.

[15] B. Bawono, P.W. Anggoro, M. Tauviqirrahman, A. P. Bayuseno, and Jamari, "The Evaluation of the Use of AFO (ankle foot orthotics) with the MOXFQ (manchester-oxford foot questionnaire) method," Atlantis Highlights in Engineering, vol. 1, pp. 657-662, 2018

[16] P. W. Anggoro, B. Bawono, M. Tauviqirrahman, A. P. Bayuseno, and Jamari, "Design and manufacturing orthotics shoe insole with optimum surface roughness using the CNC milling," Journal of Engineering Science and Technology, Vol. 14, No. 4, pp. 1799-1819, 2019.

Copyright $\odot$ by the authors. Licensee TAETI, Taiwan. This article is an open access article distributed under the terms and conditions of the Creative Commons Attribution (CC BY-NC) license (https://creativecommons.org/licenses/by-nc/4.0/). 